\title{
The Dual Quadbrain Model and Modular Consciousness
}

\author{
Bruce Eldine Morton \\ John A. Burns School of Medicine, University of Hawaii, Honolulu, USA
}

Copyright $\mathrm{O} 2017$ by authors, all rights reserved. Authors agree that this article remains permanently open access under the terms of the Creative Commons Attribution License 4.0 International License

\begin{abstract}
A multiple module model of human consciousness is needed because several powerful subconscious elements have been found which strongly influence behavior. Recognition of the existence of brain-mind modules is as old as written history. Recently, McLean's evolutionary Triune Brain model has been expanded to Morton's Dual Quadbrain Model of modular consciousness. The bilaterality of the cerebrum is necessary because the left hemisphere is specialized in top-down logic, which cannot occur in the same space as the right hemisphere's bottom-up orientation. These differences have led to the concept of hemisity, which is based upon which side of the anterior cingulate, part of the executive ego, was larger, thus determining the right or left brain-orientation of the individual. The cerebellum which is also bilateral, houses Freud's Superego with its life and social orientation, so often emulated in religion. It also houses the Thanatos, Reactive Mind, Pain Body, and mutated developmental arrest repair program (xDARP), source of conflict between mates leading to more than $50 \%$ to divorce in the US. Lastly, the brain core is also bilateral with Freud's ferocious wolf-Id on one side and the loyal and supportive dog-Id on the other. These produce the hostile or friendly ultimate brain output. With these seven brain modules active, we are a formidable society of seven.
\end{abstract}

Keywords Brain Mental Modules, Bilateral Brain, Hemisity, Subconscious, Unconscious, Preconscious

\section{Introduction: Why a Multiple Mind Model of Consciousness is Needed}

A single consciousness model of mind has never been able to account for the complexities of human behavior. Failure to understand, predict, or control behavior has resulted in enormous tragedy and suffering and has retarded brain research. That is, a single consciousness model has not accounted for the following: identity, volition, awareness, causality, responsibility, introspection, altruism, hypnosis, schizophrenia, hallucinogens, or spirituality. Furthermore, a single consciousness model cannot account for our many subconscious behaviors. "Yes, Tommy. We only use $10 \%$ of our brain. The other $90 \%$ uses us!" That traditional hidden $90 \%$ is actually the sum of the subconscious activities of our evolutionarily evolved, bilateral four-layered brain.

\section{Earlier Multiple Mind Models}

In Greek-Platonic philosophy, the mind usually consisted of four parts: the soul, reason, the competitor, and appetite. In the religions of Judaism, Christianity, and Islam, there were often three consciousness elements: $\mathrm{Me}$, the victim of fate; the Devil made me do it; and God help me! More recent psychological thought has used up to four consciousness elements. For example, Harvard Professor, William James [1] proposed the existence of the Material Self, the Social Self, the Spiritual Self, and Pure Ego. Early in the $19^{\text {th }}$ century, Sigmund Freud [2] also felt there were four mind elements. They were Normal Consciousness, about which everyone knew, and three subconscious entities, which he called the Id, Ego, and Superego. Although he did not know the brain elements producing them, these have now become obvious, as described here.

Surprisingly, many neuroscientists today hold to the universal childhood belief in a single consciousness meme, which asserts that we know about and are responsible for everything we do and are. A notable exception was Paul McLean [3] at the National Institutes for Health in the USA who developed the Triune Brain Model, which consisted of three increasingly recent evolutionary layers. They were the Reptilian System, the Paleo-Mammalian (limbic) System, and the Neomammalian System, as illustrated in Figure 1.

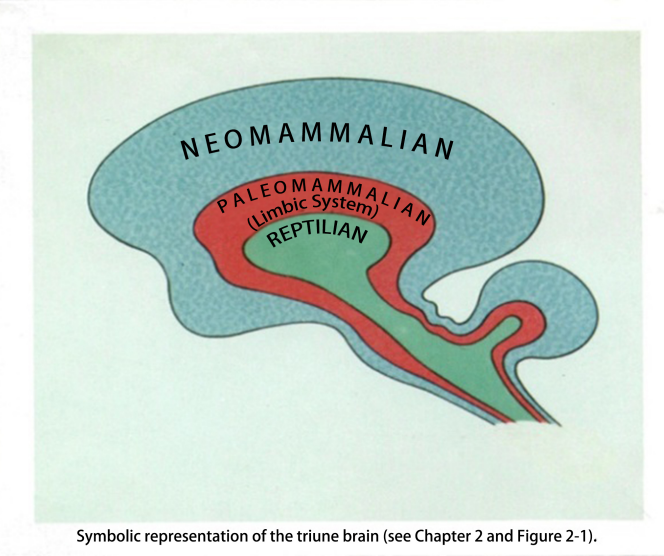

Figure 1. McLean's Triune Brain 


\section{The Quadrimental Brain Model}

However, McLean's Triune Brain Model did not accommodate later discoveries of the many non-motor behaviors produced by the hindbrain cerebellum, an obvious major brain structure whose number of small cells totaled more than the entire rest of the brain. The neuronal activities of the cerebellum were not present in his model. For example, cerebellar autostimulation by institutionalized criminals remarkably reversed their murderous rage, turning them into cordial, socially appropriate individuals [4]. Further, the sites of Primary Memory have been found to be in the cerebellum [5]. The cerebellum is also required for language syntax generation [6]. Surprisingly, the cerebellum is also activated during faith healing, hypnosis, and during "control psychosis." Therefore, McLean's Triune Brain Model was expanded into the Quadrimental Brain Model by Bruce Morton [7] in 1985, (Figure 2). The four layers of this model included the 1. Cerebral System which "imagines and describes", 2. Limbic System which possesses ("has"), and controls, 3. Cerebellar System which "is" and knows, and 4. Striatal-Brain Core System which "does" the final output.

\section{THE QUADRIMENTAL BRAIN}

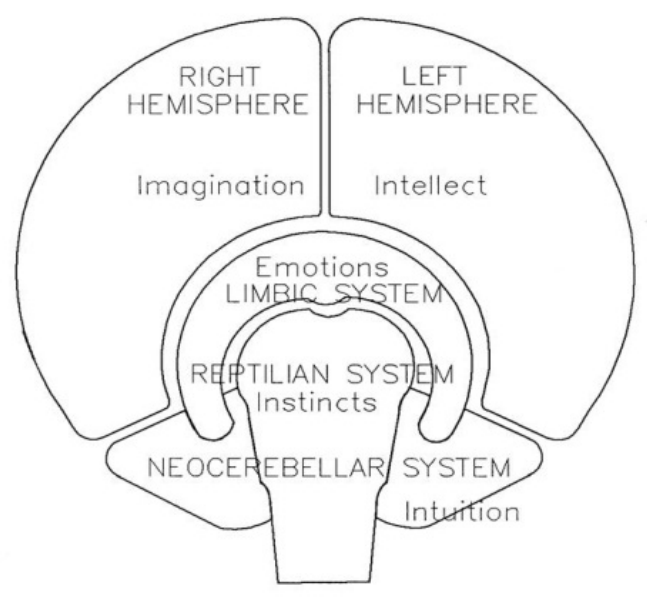

SOURCE OF HUMAN EXPERIENCE

Figure 2. The Quadrimental Brain

\section{The Need to Move to a Dual Quadbrain Model}

Yet, the entire vertebrate central nervous system is bilateral. That is, all of its structural elements are paired with each other on either side of the midline, like the two cerebral hemispheres are, for example. Each of these quadri-layered bilateral elements of the quadrimental brain have been discovered not to be simple duplicates, but to provide a base for the two important elements for that level required brain function. That is, in general the left side appears specialized for self-survival conflicts against other organisms in the form of "win-lose" competition, if need be, fights to the death. The right sided members of the Quadrimental Brain appear to be dedicated to interactions at the next higher universe level, that of social relations within the family, where it is completely nonviolent in the form of "win-win or no deal."

The sole exception to brain bilaterality is the central pineal gland, an endocrine organ. That unique centrality led the French philosopher Rene Descartes in 1637 [9] to propose the pineal gland to be the seat of the soul. More recently, the hallucinogen DMT (dimethyl tryptamine) has been found in the pineal gland of sheep [10] and in human urine at particularly high levels in schizophrenics [8]. This gives substance to Descartes' seat of the soul idea and is consistent with the fact that DMT is also released under near-death circumstances to produce a profoundly altered state of consciousness, reminiscent of that produced in normal people by the administration of the endogenous hallucinogen DMT.

\section{Bilaterality of the Cerebral Cortex}

Awareness of sidedness in brain function appears to be as old as written history. For example, Diocles of Carystus in the $4^{\text {th }}$ century BC wrote: "There are two brains in the head, one which gives understanding, and another which provides sense-perception. That is to say, the one which is lying on the right side is the one that perceives: with the left one, however, we understand." [11]. Although Diocles may have been the first to write about brain laterality, Marc Dax [12] was the first in the modern era to note a difference in function between the cerebral hemispheres. In 1836, he reported victims of stroke or other injury to the left hemisphere (LH), but not the right hemisphere $(\mathrm{RH})$, could not speak. This hemispheric asymmetry for language was also thought to be tied to contra-lateral hand preference [13]. Among those $90 \%$ of humans who are right handed [14), language is located in the LH in over $95 \%$ of them [15]. Of the remaining about $10 \%$ of left-handed individuals, some $60 \%$ of these also have language in their left cerebrum [16]. Thus, the LH houses language ability in at least 9 out of 10 humans.

Nearly a century passed before reports of any further manifestations of hemispheric laterality. Then, a large study by Weisenberg and McBride [17]. demonstrated a $\mathrm{RH}$ superiority for visuospatial skills. More recently, differences in cerebral structure and function were found in "split-brain" subjects. These individuals had been produced by treatment for intractable epilepsy by severing their corpus callosum, the only cerebral connection between the two hemispheres, thus limiting the spread of seizures from one side to the other $[18,19,20]$. 
Based upon the surprisingly different responses obtained by the interrogation of each of the disconnected hemispheres of split-brain subjects $[19,20,21]$, investigators proposed that the right and left cerebral hemispheres are characterized by in-built qualitatively different and seemingly mutually antagonistic modes of data processing, necessarily separated from interference by the major longitudinal fissure of the brain $[18,22]$. It is as if the brain uses opposite but complementary orientations to analyze what is going on in terms of survival.

In this model of the cerebrum (Table 1), the left hemisphere is specialized in top-down, deductive, cognitive dissection of local detail, while the right hemisphere orientation is a bottom-up, inductive, perceptual synthesis of global structure $[18,20]$. Known laterality differences between them reinforced this context. That is, there are striking differences in input to each hemisphere, differences in internal neuronal-columnar architecture, and differences in hemispheric output $[23,24,25,26,27]$.

Supporting the above view of opposite processing modes between the cerebral hemispheres is a large body of evidence, only briefly summarized here, that the left cerebral hemisphere in most right-handed individuals manifests facilities for language [16], has an orientation for local detail [28], has object abstraction-identification abilities [23], and appears to possess a hypothesis generating, event "interpreter" $[20,29,30]$. In contrast, the right hemisphere excels in global analysis [28, 31, 32], object localization [23], facial recognition [33] and spatial construction [34].

\section{The Emergence of Hemisity}

It is of interest that within this huge group of right-handed, LH-dominant speakers, the existence of two major human sub-populations has repeatedly been inferred, whose characteristic thinking and behavior styles differ in a manner that appeared to mirror the properties of the asymmetric hemispheres. That is, in some right-handed LH-languaged individuals, left hemisphere traits were proposed to be ascendant, producing a "left brain-orientated" thinking and behavioral style $[31,35]$. Such left brain-oriented persons were top-down, important detail, deductive "Splitters." Yet, in other right-handed, LH-languaged persons, right hemisphere traits are thought to be more prominent resulting in a contrasting Right brain-oriented style [36, 37], currently viewed as bottom-up, big picture, inductive "Lumpers".

The original permanent assignment of the term "hemispheric dominance" to language laterality forced the creation of a different term that attempted to quantify these behavioral style differences within this huge group of right-handed LH-languaged individuals. That first attempt at this was under the term "hemisphericity" $[38,39]$ That approach created an enormous cul-du-sac in the literature of hundreds of papers, all ultimately debunked [40]. This was because individual hemisphericity was improperly defined as some unique point on a gradient between left and right brain extremes. Because, few were willing to place themselves at the extremes, this resulted in very weak evaluators, that of Zenhausern being the strongest [41].

Table 1. The Contrasting Orientations of the Cerebral Hemespheres

\section{Left Cerebrum "Reporter": Hears-Says}

Views the right foreground= Important details

Wiring is local, convergent, top-down, serial

Deductive (general to particular): Understands

Stays within data limits: Literal, Surface view

Sees Content: types within a universe level

"Splitter": Reductive, breaks-down, extracts

Abstract: digital, language, mathematics

Symbolic: a word is worth a 1000 pictures

Declarative-Auditory working memory

Intelligence quotient, IQ: reports, interprets

Tool making: Technology
Right Cerebrum "Imagination": Sees

Views entire background = Big picture

Is global, divergent, bottom-up, parallel

Inductive (particular to general): Conceptual

Projects beyond limits: Intuitive-Metaphor

Sees Context: hierarchies of univ. levels

"Lumper"Builds-up higher order processes

Visual: analogue, imagination, projection

Visio-spatial: picture worth a 1000 words

Visual-spatial working memory

Intelligence g-factor, evaluates, knows

Tool using: Civilization 
After a quarter of a century, of politically correct silence regarding hemispheric laterality, Morton [42] redefined hemispheric laterality in a more functional manner, called "hemisity". He posited that brain laterality was not to be defined as on an individual gradient. Rather, one was born either genetically completely left brain-oriented or completely right brain-oriented. This produced robust data and led to the discovery by MRI of two neuroanatomical differences between right and left brainers. First, right brainers tend to have larger corpus callosi than left brainers
$[41,43]$. Second, the asymmetric anterior cingulate was largest on the brain side of hemisity. The latter observation became the primary standard for hemisity and permitted the further calibration of the several pre-existing biophysical and questionnaire based assessors [44]. This led to a table (Table 2) of "either-or" left and right oriented behavioral choices, each approximately $80 \%$ accurate, but when combined producing $96 \%$ certainty of hemisity identity. This entire work has been integrated and reviewed [45].

Table 2. Thirty Behavioral Correlates of Hemisity

\section{LOGICAL ORIENTATION}

Analytical (stays within the limits of the data)

Uses logic to convert objects to literal concepts

Decisions based on objective facts

Uses a serious approach to solving problems

Prefers to maintain and use good old solutions
Sees the big picture (projects, predicts)

Imagines, sees contexts, and metaphors

Decisions based on feelings, intuition

Use playful approach to solving problems

Would rather find better new solutions.
Daydreams are not vivid

Doesn't often remember dreams

Thinking often consists of words

Comfortable and productive with chaos

Can concentrate on many things at once

Often thinking tends to ignore surroundings

Often an early moming person

\section{TYPE OF CONSCIOUSNESS}

Has vivid daydreams

Remembers dreams often.

Thinking often consists of mentalimages

Slowed by disorder and disorganization

Ponders one thing in depth at a time

Observant, in touch with surroundings

Often a late night person
Conservative and Cautious

Sensitive in relating to others

Tend to avoid talking about emotional feelings

Suppresses emotions as overwhelming

Would self-medicate with depressants

\section{FEAR LEVEL AND SENSITIVITY}

Bold and Innovative

Intense in relating to others

Talks about own and others emotions

Seeks to experience or express emotions

Would self-medicate with stimulants

\section{SOCIAL AND PROFESSIONAL ORIENTATION}

Independent, hidden, private, and indirect

Avoids seeking evaluation by others

Usually tries to avoid taking the blame

Does not praise others nor work for praise
Interdependent, open, public, and direct Seeks frank feedback from others Takes blame, blames self, or apologizes Praises others, works for praise of others

\section{PAIR-BONDING STYLE AND SPOUSAL DOMINANCE}

After an upset with spouse, needs to be alone

Tolerates mate defiance in private

Needs little physical contact with mate

Tends not to be very romantic or sentimental

Prefers monthly larger reassurances of love

Thinks-listens quietly, keeps talk to minimum

Does not read other people's mind very well

Often feels their mate talks too much

Lenient parent. kids tend to defy
After spousal upset, needs closeness

Cannot tolerate mate defiance in private

Needs a lot of physical contact with mate

Tends to be romantic and sentimental

Likes daily small assurances of love

Thinks-listens interactively, talks a lot

Good at knowing what others think.

Feels mate doesn't talk or listen enough. Strict. kids obey and work for approval 
In terms of modular consciousness, the conclusion regarding differences between the cerebral hemispheres is that under normal conditions, our conscious thinking is restricted to that of our left hemisphere Reporter and right hemisphere Imagination. As to the origin of an individual's hemisity, it appears to be genetically determined before birth $[46,47]$,

\section{Laterality of the Executive Ego Determines Hemisity Subtype}

Hemisity results from localization of the Executive Ego within either the left or right cingulate cortex, (Table 3), with consequent reduced access to the skills of the more distant asymmetric hemisphere. One of its functions is to chose whether to use "win-lose" violent competition-oriented brain elements of the "Id" to solve life's inevitable problems, or to use "win-win" cooperating brain elements of the "Superego" to enhance survival.
In the last two millennia, the ego has evolved to become enormously developed [48]. Its top down discriminations have expanded into all areas of life. Its specialty is deductive distinction, that is, how things differ from each other. This has produced an explosion in mathematics and quantitative science, which has freed us from having to be a primary food source. This breakthrough has fueled the ongoing exponential growth of the population, the development of science, and is currently fueling our flights to the Moon and Mars.

In terms of modular consciousness, the ego makes these discrimination at least a one second before we, up in the cerebrum, become aware of its choices [49, 50]. We then simply go along and rationalize its decisions, as if we made the choice ourselves (Figure 3). The ego is also the source of the hexadyad primary emotions [51], by which it motivates other brain elements to act. If it doesn't succeed, it also contains an extensive group of ego defenses of the Id [52, 53] to rationalize its failures.

Table 3. The Side-Dependent Properties of the Unilateral Executive Ego

\begin{tabular}{ll}
\hline LP = a Left Brain-Oriented Person & RP = a right brain-oriented person \\
Left anterior cingulate is the largest in LPs & Right anterior cingulate is the largest in RPs \\
Can reach R-brain via corpus callosum. & Canreach L-brain via corpus callosum \\
Left limbic system: thinks it controls everything & Right limbic system: Dyslexia if memory on left. \\
Produces Ego Defenses of Id, confabulates & Knows faces, expressions, body talk \\
Asks: how is this different than earlier-similar events? & Asks: how is this the same as earlier-similar events? \\
Distinguishes differences by deduction & Detects similarities by induction
\end{tabular}

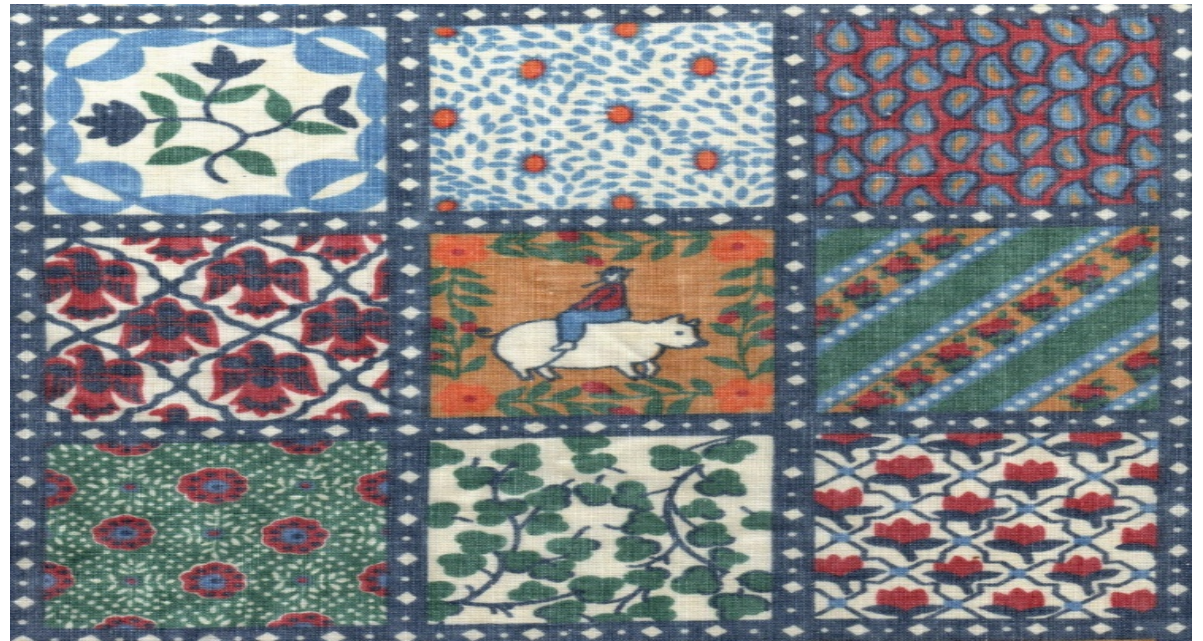

Figure 3. Who is in Control, Executive Ego or Intellect? A Hint from a Hawaiian Shirt 
Table 4. The Bilateral Cerebellar Social Brain

\begin{tabular}{|c|c|}
\hline Thanatos: is, Hates & Eros: IS, Loves (Superego) \\
\hline $\mathrm{xDARP}$ Memory: is too charged to access & Primary Memory \\
\hline Our "Dark Side" Intellect & Our "Higher Intelligence" \\
\hline Evil, Devil-within, Insanity & Good, God-within, Wisdom \\
\hline Diabolic, Superstitious & Inspired Source, Religious \\
\hline Rejects what IS, Resists it. & Accepts what IS, Chooses it as perfect \\
\hline Angry, Failing, at Effect & Happy, Successful, at Cause \\
\hline Victim in one's Universe & God in one's Universe \\
\hline Sees no possibility, Nightmares & Sees possibility, Visions \\
\hline Negative, Pessimistic & Positive, Optimistic \\
\hline Parasitic, Wasteful & Synergistic, Conservative \\
\hline Avoids work, Chaotic & Works hard, orderly \\
\hline Irresponsible, Lies, Cheats, Steals & Responsible, Honest, Ethical, Non-violent \\
\hline Revengeful, Mutilates, Kills & Guilt, Conscience \\
\hline
\end{tabular}

As indicated above, the laterality of the ego shows itself in terms of a person's inborn hemisity [45]. If the larger side of the cingulate cortex is on the left, the person will be a left brain detail-oriented conservative person. If it is on the right, the person will be a right brain oriented big picture oriented.

This brings to three the brain modules discussed thus far: the Intellect, the Imagination, and the Executive Ego.

\section{Laterality of the Cerebellum: The Divine Superego and the Diabolic Thanatos}

Next, we turn to the physical and social behavior produced by bilateral cerebellum, the brain structure containing more neurons and glia that the entire rest of the brain. In a way, the cerebellum appears to operate as a second independent brain system. It uses the regularity of its structure to contain one's primary memory [5] in the form of a continuous time track that began prenatally and keeps recording until death. This enormous record gives it knowledge of time and the sequence of events, to establish causality and morality. Its skill is in the simultaneous coordination of multiple elements, for example, the coordination of an organism's muscles, tendons, and bones to produce the infinity of efficient and graceful movements required for life and its expression. This early manifested itself in the coordinated behavior of large groups of social organism: the swarming of bees or locusts, the schooling of fish, the flocking of birds, migration of reindeer, and the trouping of monkeys.

Later, the cerebellum was found to be required for language syntax, that is, the coordination of thousands of words about "who did what to whom" to produce meaning via accurate, specific descriptions. Thus, the cerebellum functions in non-motor associative learning, working memory, visuo-spatial abilities, verbal fluency, syntax, reading, and writing [6]. Many of these non-motor activities have been localized to the right side of the cerebellum, which is connected to the left cerebral language hemisphere [6] (Table 4.)

In addition to these God-like traits, separate non-Id based antisocial character of the cerebellum has also been noted. This has been termed the Todestribe by Freud and Thanatos by others [2], the Reactive Mind, by Hubbard [54] and the Pain Body by Tolle [55]. These repetitive behaviors have recently been recognized as the action of a mutated developmental arrest repair program (xDARP) (Morton, 2011). This broken program, unaware of its lost capacity, compulsively still attempts to repair early childhood developmental arrests. It does so by dogged repetition of the following specific behaviors, which are the source of endless conflict between friends and lovers, and lead to the incredible $>50 \%$ divorce rate we presently have in the US.

$\mathrm{xDARP}$-induced repetitive behaviors of the perpetrator include the following: 1. By subconscious infatuation, it locates, and seduces a "parent figure" target from the present environment, often of the opposite sex. When, the target finally expresses their love and acceptance of the xDARP-activated person, often marrying them, the xDARP feels safe to act. It does so by, 2. age regression, 3. transferring upon the victim the unresolved childhood conflict that led to their original developmental arrest-deficit. Then it, 4. Sets up the ancient conflict again to finally gain control. It then, 5. Acts out, by compulsively repeating the developmental theme, and, 6. escalates the struggle to gain control of their "parent figure" target. After a few months of this, the target begins to think that something is wrong, that these endlessly repeated unresolved conflicts appear to be 
increasingly insane. This; often activates the victim's own $\mathrm{xDARP}$ and in the resulting intense conflict, their marriage crashes and burns. This irreversibly damages their children to repeat the cycle in the next generation.

\section{Laterality of the Brain Core}

Lastly, we come to the bilateral brain core Id (Table 5). The left side can act as a ferocious wolf, fighting enemies to the death. Or, under other conditions, the right side of the brain core serves to cooperate, like man's best friend, the dog, or a servant; where the Ego's wish is its command. These two brain core Ids are the final output effectors of the entire brain.

To sum up:

1. Right cerebral Imagination

2. Left cerebral Reporter

3. Bilateral limbic Executive Ego

4. Cerebellar Superego

5. Cerebellar xDARP

6. Brain core wolf Id

7. Brain core dog Id

Seven conscious brain modules [45]. Thus, we each are a formidable Society of Seven (Figure 4).

Table 5. The Bilateral Brain Core:

Left Pons

Self-preservative instincts and drives

Punished Avoidance

Sensitive Introvert

Defensive Aggression

Sympathetic Nervous System Stress Response

Antisocial, Rejects others as aliens

Immediately gratifying

Defies Authority

Adversarial, Rigid

Must be right, win, dominate, look good

Win-lose rules, winner takes all

Size based peck order

Follows winners, bullies losers

Type A, PTSD, Alexithymia

\section{Right Pons}

Species preservative instincts and drives

Rewarded Approach

Intense Extrovert

Sex-Reproduction

Parasympathetic Nervous System Rest and Repair Social, Accepts others as family

Defers self-gratification

Defers to Authority

Cooperative, Adapts

Must tell the truth, assist, serve at all costs

Win-win or no deal, winnings shared

Leadership based upon excellence

Honors wisdom first, then

honors others as oneself. 


\section{THE DUAL QUADBRAIN OF MAMMALS}

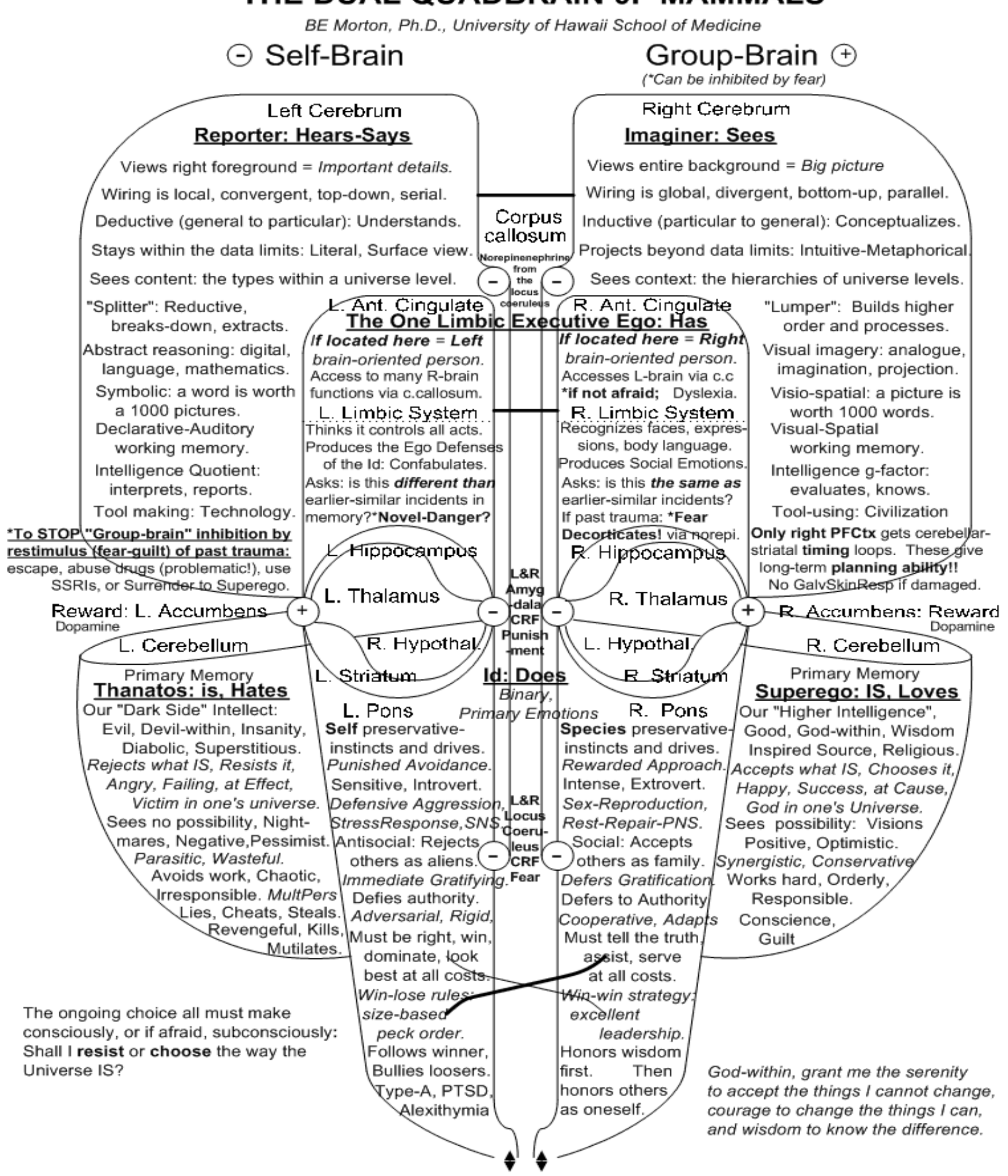

Figure 4. The Dual Quadbrain if Mammals

\section{Who is in Control? Whoever it is that Gains Access to One's Seat of Consciousness}

Whoever of our seven consciousness modules occupies our brain's seat of control at a given time determines our behavior. We cannot easily tell who that is, except by our associated thoughts and behavior. I may be playing my guitar and singing sweetly to my darling with my right hemisphere Imagination, when along comes another guy who pats her fanny. I next find myself in a violent rage with my wolf Id activated to kill. Yet, it's all the same to me. Thus, it is usually a variation of the "Great Controversy" between the self-oriented Id and the family oriented, non-violent self. 
Clearly, awareness of modular consciousness is an essential tool toward peace and harmony. This topic has been also described in in a book length format [56].

\section{REFERENCES}

[1] James W. (1878). Principles of Psychology, Holt, New York, republished by Dover, New York 1950.

[2] Freud S (1922). Beyond the Pleasure Principle. Trans. by C. J. M. Hubback. Vienna: International Psycho-Analytical Society, London.

[3] MacLean PD. (1990). The triune brain in evolution: role in paleocerebral functions. Plenum.

[4] Heath RG. (1977). Modulation of emotion with a brain pacemaker: Treatment for intractable psychiatric illness. Journal of Nervous and Mental Disease, 165, 300-317.

[5] Andreasen NC, O'Leary DS, Paradiso S, Cizadlo T, Armdt S, Arndt S, Watkins GL, Ponto LL, Hichwa RD. (1999). The cerebellum plays a role in conscious episodic memory retrieval. Human Brain Mapping, 8, 226-234.

[6] Buckner RL (2013). The Cerebellum and Cognitive Function: 25 Years of Insight from Anatomy and Neuroimaging, Neuron, $80,807-815$.

[7] Morton, BE. (1985). Conflict and the quadrimental brain hypothesis. International Society for Research on Aggression Abstracts, 13, 106.

[8] Rodnight R, Murray RM, Oon MC, Brockington IF, Nocholis P, Birley JL. (1976). Urinary dimethyltryptamine and psychiatric symptomatology. Psychological Medicine, 6, 649-657.

[9] Descartes R. (1974). Discourse on Method and The Meditations, trans. F. E. Sutcliffe, Harmondsworth.

[10] Beck O, Bosin R. (1969). Analysis of 5-methosytryptamine in brain by gas chromatography mass spectrometry. Biological Mass Spectrometry, 6, 19-22.

[11] Lockhorst GJ. (1985) An ancient Greek theory of hemispheric specialization. Clio Medica, 17, 33-38.

[12] Dax M. (1785). Lésions de la moitie gauche de encéphale coincident avec doubli des signes de la pensée. Gazette Hebdomadaire de Medécine et de Chirurgie, 2(2eme serie), m 2. (read at Montpellier in 1836.)

[13] Broca, P. (1865): cited in S. Dimond, The Double Brain. (London: Churchhill-Livingstone, 1972).

[14] Coren, S. The left-hander syndrome: The causes and consequences of left-handedness (Free Press, New York, 1992).

[15] Smith, LC, Moscovitch M. (1979). Writing posture, hemispheric control of movement and cerebral dominance in individuals with inverted and noninverted hand postures during writing. Neuropsychologia, 17, 637-644.

[16] Levy J, Reid M. (1976). Variations in writing posture and cerebral organization. Science, 194, 337-339.
[17] Weisenberg T, McBride, KE. Aphasia: A clinical and psychological study. New York: Commonweath fund, 1935 (cited in Springer, S.P. and Deutsch, G. Left brain, right brain: Perspectives from cognitive neuroscience. $5^{\text {th }}$ Ed. $\mathrm{p} 361, \mathrm{~W} . \mathrm{H}$. Freeman, New York, 1999.)

[18] Sperry RW. (1982). Some effects of disconnecting the cerebral hemispheres. Science, 217, 1223-1226

[19] Gazzaniga, MS, Bogen JE, Sperry RW. (1962) Some functional effects of sectioning the cerebral commissures in man. Proceedings of the National Academy of Sciences, USA 48, 1765-1769.

[20] Gazzaniga MS. (2000). Cerebral specialization and interhemispheric communication: Does the corpus callosum enable the human condition? Brain, 123, 1293-1326.

[21] Geschwind, Iacoboni, Mega, Zidel, Cloughesy, \& Zaidel, (1995). Alien hand syndrome: interhemispheric motor disconnection due to a lesion in the midbody of the corpus callosum. Neurology, 45, 802-808.

[22] Levy J. (1969). Possible basis for the evolution of lateral specialization of the human brain. Nature, 224, 614-615.

[23] Kosslyn SM. (1987). See and imagining in the cerebral hemispheres: A computational approach. Psychological Reviews, 94, 148-175.

[24] Kosslyn SM, Chabris CF, Marsolek CJ. (1992). Categorical versus coordinate spatial relations: computational analyses and computer simulations. Journal of Experimental Psychology: Human Perception and Performance, 18, 562-577.

[25] Hutsler J, Galuske RAW. (2003). Hemispheric asymmetries in cerebral cortical networks. Trends in Neurosciences, $26,428-435$.

[26] Jager G, Postma A. (2003). On the hemispheric specialization for categorical and coordinate spatial relations: A review of the current evidence. NNeuropsychologia, 41, 504-515.

[27] Stephan KE, Fink GR Marschall JC. (2006). Mechanisms of hemispheric specialization: insights from analysis of connectivity. Neuropsychologia, 45, 209-228.

[28] Robertson LC, Lamb MR. (1991). Neuropsychological contributions to theories of part/whole organization. Cognitive Psychology, 23, 200-330.

[29] Wolford G, Miller MB, Gazzanaga M. (2000). The left hemisphere's role in hypothesis formation. Journal of Neuroscience, 20:RC64, 1-4

[30] Gazzaniga MS. (1989). Organization of the human brain. Science, 245. 947-952.

[31] Fink GR, Halligan PW, Marshall JC, Frith CD, Frackowiak RS, Dolan JR. (1996). Where in the brain does visual attention select the forest and the trees? Nature, 382, 626-628.

[32] Van Kleeck MH. (1989). Hemispheric differences in global versus local processing of hierachal visual stimuli by normal subjects: New data and a meta-analysis of previous studies. Neuropsychologia, 27, 1165-1178.

[33] Milner B. (1968). Visual recognitions and recall after right temporal lobe excision in man. Neuropsychologia, 6, 101-109 
[34] Sperry, RW. (1968). Hemisphere disconnection and unity in conscious awareness. American Psychologist, 23, 723-733.

[35] Springer, SP, Deutch G. (1998). Left brain, right brain: perspectives from cognitave neuroscience. Fifth edition, W.H. Freeman, N.Y.

[36] Davidson RJ, Hugdahl K. (1995). Brain Asymmetry, MIT Press, Cambridge, MA.

[37] Shiffer F. (1996). Cognitive ability of the right hemisphere: possible contributions to Psychological Function. Harvard Review of Psychiatry, 4,126-138.

[38] Bogen JE. (1969) The other side of the brain II. An appositional mind. Bulletin of the Los Angeles Neurological Society, 34, 135-162.

[39] Bogen JE, DeZure R, Ten Houten WD, Marsh JF. (1969). The other side of the brain. IV. The A/P ratio. Bulletin of the Los Angeles Neurological Society 37, 49-61.

[40] Beaumont G, Young A, McManus IC. (1984). Hemisphericity: A critical review. Cognitive Neuropsychology, 1, 191-212.

[41] Zenhausern R. (1978). Imagery, cerebral dominance, and style of thinking: A unified field model. Bulletin of the Psychonomic Society, 12, 381-384.

[42] Morton BE. (2010). Behavioral laterality advance: Neuroanatomical evidence for the existence of hemisity. Personality and Individual Differences 49, 34-42

[43] Morton BE. Rafto SE. (2006). Corpus callosal size is linked to dichotic deafness and hemisphericity, not sex or handedness. Brain and Cognition, 62, 1-8.

[44] Morton BE. (2012). Left and right brain-oriented hemisity subjects show opposite behavioral preferences. Frontiers in Physiology, 3, doi: 10,3389/fphys.2012.00407
[45] Morton BE. (2013). Behavioral laterality of the brain: support for the binary construct of hemisity. Frontiers in Psychology, 4, doi: 10,3389/fpsyg.2013.00683

[46] Crowell DH, Jones RH, Kapuniai LE, Nakagawa JK. (1973). Unilateral cortical activity in newborn humans: An early index of cerebral dominance. Science, 180, 205-208.

[47] Wada JA. (1977). Prelanguage and fundamental asymmetry of the infant brain. Annals of the New York Academy of Science, 299, 370-379.

[48] Jaynes J. (1976). The origin of consciousness in the breakdown of the bicameral mind. Houghton Mifflin Company, Boston.

[49] Libet B. (1965). Cortical activation in conscious and unconscious experience. Perspectives of Biology and Medicine, 9, 77-86.

[50] Libet B. (1989). The timing of a subjective experience. Behavioral and Brain Sciences, 12, 183-185.

[51] Morton BE. (2011) Neuroreality, Megalith Books, Miami. (amazon.com) Randy L. Buckneri Search for articles by this author

[52] Freud S. (1894). The neuro-psychoses of defense. SE, 3: 41-61.

[53] Freud S. (1896). Further remarks on the neuro-psychoses of defense. SE, 3: 157-185.

[54] Hubbard LR (1950). Dianetics: The modern science of mental health, East Grinstead, Sussex, England.

[55] Tolle E (1999). The Power of Now. A Guide to Spiritual Enlightenment. Namaste, Vancouver.

[56] Morton BE. (2014). Modular Consciousness. Megalith Books, Miami.(amazon.com) 